\title{
Are UK elections conducted with integrity, with sufficient turnout?
}

Across the world, there are many countries where elections take place but are rigged by governments or unfairly conducted. And even in core liberal democracies (like the United States) political parties have now become deeply involved in gerrymandering constituencies and partisan efforts at 'voter suppression'. Toby $\mathbf{S}$ James looks at how well elections are run in the UK, and whether the systems for registering voters and encouraging turnout are operating effectively and fairly.

\section{What does democracy require for the conduct of elections? And how are voting, candidacies and fair competition facilitated?}

Governmental and legislative offices are open to popular competitive elections. All citizens have the right to take part in the electoral process. All parties, interests and groups assign great importance to maintaining universal and equal voting rights and to encouraging electoral participation.

All votes count equally. So constituencies for all legislatures are (broadly) equal in size; and seats are (broadly) distributed in proportion to population numbers. Some variations in the population sizes of seats in order to facilitate more effective 'community' representation are allowable.

The registration of voters is impartially organised in timely, speedy, convenient and effective ways. It maximises the ability of all citizens to take part in voting. Resources are available to help hard-to-register groups to be enrolled on the register.

Voting in all elections is easy to do and the administrative costs for the citizen are minimised. Polling stations are local and convenient to access, there are no long queues for voting, and voters can also cast votes conveniently by mail or online. Arrangements for proxy voting are available. All modes of voting are free from intimidation, fraud-proof and robust.

All citizens can stand for election as candidates, and they face no onerous regulatory or other barriers in doing so. Some requirements for signatures or deposits are allowable in order to obviate frivolous candidacies, but they must be kept low and proportional to the seriousness of the offices being contested. All parties and groups 
assign top importance to maintaining candidacy rights and facilitating effective electoral competition and maximum choice for voters.

Political party names and identifying symbols can also be registered to prevent 'passing off' strategies designed only or mainly to confuse voters. (Registering party names is also essential in most PR systems where candidates are elected off party lists.) But otherwise party or candidacy names may be freely chosen, and candidates can describe themselves in any legal way.

All aspects of the electoral process are run impartially by trained, professional staffs in secure ways that minimise any opportunity for fraud. Election administrators have the legal ability to curb electoral abuses and to ensure that all candidates campaign legally and within both the electoral rules and the normal legal requirements to show respect for other citizens. Police and prosecution services impartially investigate and pursue all allegations of electoral misconduct or corruption and prosecute when necessary in a timely manner.

Incumbent governments at the national level and sitting MPs or members of legislatures at constituency level must compete at elections on fully equal terms with all other parties and candidates. They enjoy no special advantages.

Elections are welcoming and safe opportunities for voters and candidates to express their views, whatever their political affiliations or social background. They are never occasions for intimidation or the worsening of social tensions.

Election conduct and counting processes should be transparent and subject to inspection by parties and candidates, and by external observers. Election processes and results should be accepted by all domestic political forces as fully free and fair, and rated in the same way by foreign observers.

The media system should be a pluralistic one, handling the reporting of elections and campaigns in a reasonably fair and diverse way. There should be no direct state interference in the reporting of elections or campaigns designed to secure partisan advantages for the incumbents or for powerful parties.

Free and fair elections are essential for the democratic process, and the UK implemented many of the requirements for them (including limits on local campaign spending) by the 1880s, although the franchise was not fully extended until 1928. The effectiveness of longunchanged 'legacy' rules, and the administration and practice of elections, often decays over time, however. As society changes, the effectiveness of old rules can drift and new problems can emerge. The UK does not have electoral irregularities on the scale commonly seen in electoral autocracies (authoritarian states or where voting takes place but under rigged arrangements) or the almost unrestricted corporate funding of elections in the USA. However, there are many pressures on electoral integrity in the UK. 


\section{Recent developments: elections, referenda and external interference}

The robustness and timeliness of the regulation of campaigns was brought into question after the 2016 Brexit vote. As with any referendum, parties were not the vehicles leading the campaign. Instead, special, one-off 'referendum fighting organisations' were established and regulated. An official campaign for Leave (Vote Leave) and another for Remain (Stronger In) were recognised by the government and Election Commission and each was assigned a relatively restrictive limit on their total spending. In addition, 'allied' organisations could register and be assigned smaller spending limits. After many allegations of malpractice by the Leave campaign, an Election Commission report found in June 2018 (two years after the vote) that Vote Leave had overspent its limit of $£ 7.6 \mathrm{~m}$ by passing a payment of $£ 650,000$ to a one-person associated 'campaign' (Be Leave, run by a graduate student). The main staffer of this organisation was on loan from Vote Leave and they used the money to hire a firm to do its social media analytics. Vote Leave claimed that the Commission had approved this at the time. Concerns were raised about how rules seemed to be easily circumvented by the campaigners and that an investigation from the Electoral Commission was only undertaken very belatedly and after a lot of prodding by media investigations.

A second closely related area has been a surge of concerns that external countries or agents can too easily influence UK elections. Suggestions have been made that units close to the Kremlin intervened in the Brexit campaign by establishing multiple robot sites to resend Leave-favouring messages on Facebook and Twitter, so as to artificially magnify their apparent salience and influence. UK investigations are only slowly proceeding, however. Concerns had been raised before, at the 2017 general election, after Russian sites were boosting Labour-favouring social media messages, according to one study. The evidence base for these worries remains very minimal, but the claims have gained currency because of better-attested evidence of Russian interventions in the Donald Trump election campaign and the threat that they would pose to electoral democracy and the international order, if true.

\section{'Dark money' and social media}

These two developments illustrate a basic concern about 'dark money' and social media. As election campaigning increasingly shifts to the internet and social media new concerns have also been raised about how undisclosed 'dark money' can influence elections and undermine political equality. Political parties are reportedly increasingly making use of data analytics to track voter behaviour on platforms such as Facebook and Twitter. This information can then be used to target advertisements in marginal constituencies. This involves a substantial investment of work and money in data analytics which does not necessarily fall within the UK's short official campaign period. Nor does this kind of expenditure clearly fit within campaign spending categories that are regulated by law. Campaign advertising laws cover TV and radio, but not social media. The playing field at electoral contests may become increasingly uneven as a result, and there is a clear need for election finance arrangements to be updated for the digital era. 
A 2018 Electoral Commission report claimed that the UK's regulatory framework governing elections in the social media age was radically inadequate. It proposed an extensive modernisation of its powers to catch up by:

requiring all online materials by candidates, parties and campaigners to state who created them;

make all campaigners declare in detail what they spent on digital activities in campaigns; require social media companies to label all election and referendum adverts with their sources and create online databases of all such materials;

give the Commission itself more investigatory powers, and the ability to levy bigger sanctions for breaches.

The government and opposition parties have not yet taken a stance on these proposals, so speedy remedial action seems unlikely.

\section{The 'age gap' in voting}

A third well publicised (and completely factual) development has been positive, namely the reversal of the long decline in turnout in UK general elections. Figure 1 shows that from the nadir of 2001, turnout rose by nearly 10 percentage points to $68.5 \%$ in the 2017 general election. Moreover, it grew substantially amongst one of those groups who were increasingly not exercising their democratic right - young people. In 2005 the UK had the largest 'age gap' of any liberal democracy in the gulf between voters over 55 and under 34. However, Figure 1 shows that turnout amongst the 18-24 and 25-34 age categories substantially rebounded in June 2017. The age gap from 2005 and 2015 was effectively halved.

Figure 1: The estimated turnout of different age groups at general elections from 1964 to 2017

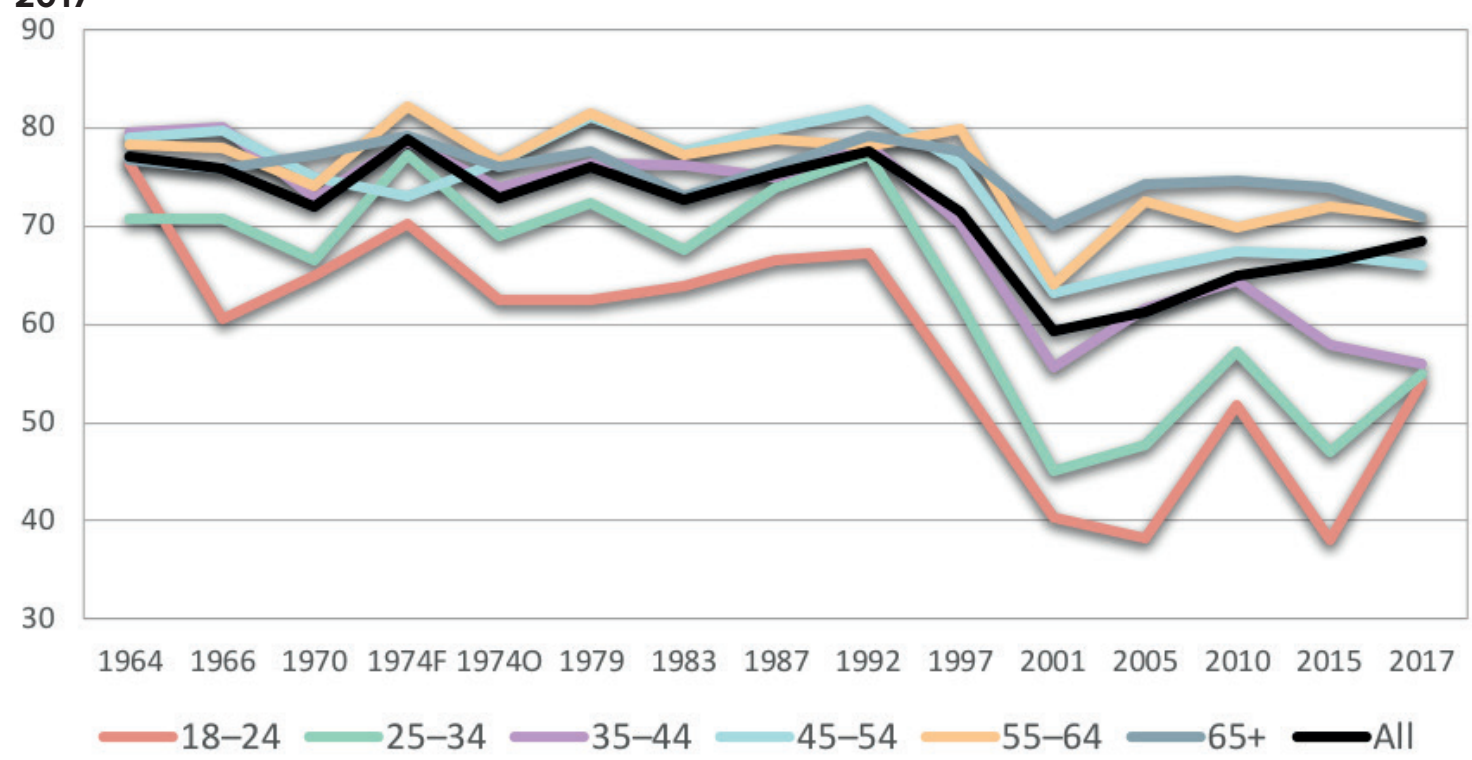

Source: Computed by author using data from the British Election Study, IPSOS Mori and BBC. 
Yet turnout remains a cause for concern. Differentials between age (and other) groups have not disappeared. The method for calculating turnout in the UK (as a percentage of registered voters) makes it look higher than it really is. The 2017 surge reflected somewhat unusual conditions and turnout remains chronically low for other electoral contests. Up to 2015 a new political cleavage had arguably opened-up based on age, education and social values rather than social class. Jeremy Corbyn's Labour Party has successfully focused on gathering support from a new electoral bloc - with the newly re-energised youth a key part of this. But whether this engagement can be sustained remains uncertain.

\section{Strengths, Weaknesses, Opportunities, Threats (SWOT) analysis}

\section{Current strengths}

Elections are generally very peaceful, and intimidation or electoral fraud rarely occur, although there are isolated problems. Election results are well respected by parties and citizens. International observers have regularly expressed 'a high level of confidence in the electoral process.'

No evidence has emerged that either flaws in campaign spending or foreign interference in either the 2016 Brexit vote or the 2017 general election changed or even significantly influenced the outcomes.

\section{Current weaknesses}

One of the biggest problems is incomplete electoral registers, owing to a system where it is an individual and not a state responsibility to ensure names are on the electoral roll. Many citizens fail to re-register because they misunderstand the electoral registration process. Estimates suggest that up to eight million citizens may be missing from registers in recent contests, around 16\% of the adult population (see below).

We noted above, there were apparent major flaws in the conduct and regulation of the 2016 Brexit referendum, plus the alleged vulnerability of UK elections to social media distortions of public debate and rigging of 'fake news'. Both raise acute new issues about whether current safeguards are adequate or adapted for modern digital conditions.

At $£ 500$ per seat, the deposit cost of contesting every seat in Britain at a general election is $£ 314,000$. This still favours the most established parties over newcomers. In 2017 candidacies for UKIP fell sharply by 346 compared to 2015; and those for the Green party by 106 . This partly reflected lack of finance, and less time to raise finance since the 2015 general election. their standing (10 for Westminster). 


\section{Current strengths}

Procedures in polling stations are simple and liberal. Currently voters do not need to show ID but just give a name and address. This makes voting very speedy to do and facilitates maximum turnout. Polling stations are also very locally situated (mainly in primary schools or community centres), and around $75 \%$ of locations stay the same from one election to another, so becoming familiar to citizens.

The UK's boundary review process responds to statute and its implementation timing is often politically delayed and influenced. However, the process of defining constituencies is independent from politicians, which prevents gerrymandering.

Electoral administration is chiefly run by professional officials in local government, who are independent from government and local politicians. The Electoral Commission is a national quasi-government body that regulates electoral finance and advises on election procedures in an independent way. It has been willing to criticise the government when necessary and recently called for its powers to be extended (see above).

A modernised online electoral registration system implemented by local authorities has enabled many last-minute voter registration applications. Timely registration for upcoming contests is much better developed than in the past.

\section{Current weaknesses}

There is an archaic, antiquated and illogical system for determining who is allowed to vote (see below). For instance, in Scotland (and soon Wales) teenagers of 16 and 17 can vote in elections for the Edinburgh Parliament and local councils, but not for Westminster MPs. In England and Northern Ireland they cannot vote at all. In addition, there remains little or no citizenship education in UK schools and available funds for this are tiny.

The robustness of the local and constituency regulation of electoral spending is problematic at the margins (see below). Constituency spending limits are set restrictively, but national spending levels by parties are completely unrestricted.

The legislative framework is 'complex, voluminous and fragmented' and in need of consultation. Isolated cases of electoral fraud remain. Some vulnerabilities in electoral registration remain. The system for securing electoral justice is archaic and slow.

Critics argue that the regulation of campaigns requires modernisation - notably citing the 2016 Brexit referendum (see above). They also say that the there is a need to update the communication of election and candidate information to citizens for the social and digital media age.

Locating electoral administrators in local governments means that many are operating under financial restraints, following many years of austerity cutbacks. Systems for registration are often dated. Arrangements for the effective online communication of results back to voters are problematic. The apparatus for communicating with voters was basically defined in the 1880s and though candidates addresses are listed on websites the approach has otherwise been little updated for the social media era. Cutbacks have especially restricted voter outreach work by local authorities. 


\section{Current strengths}

Civil society groups and NGOs (such as 'Bite the Ballot') have organised to register and engage voters. They helped to set out policy ideas through a parliamentary group. Voter advice applications also seek to reach people at general elections who are not normally politically engaged. And sites such as Democracy Club and Democratic Dashboard contribute to the provision of information to citizens.

\section{Current weaknesses}

Further deficiencies in UK elections lie outside the area of 'electoral integrity' itself. The Westminster electoral plurality voting system (also used in English and Welsh council elections) often produces highly disproportional results (see Chapter 2.1). In the media system the newspaper coverage of candidates and parties remains systematically unbalanced.

\section{Future opportunities}

The Scottish government may bring legislation forward to reform Scottish electoral law and Welsh government is reviewing local elections in Wales (see Chapter 6.4). This could also provide opportunities for innovation and learning across the UK.

The Brexit negotiations offer an opportunity for the concept of citizenship to be redefined and electoral rights to be realigned.

UK-wide pilots of automatic registration could lead to cost efficiency savings, but may also strengthen levels of voter registration. The Missing Millions report from the All Party Group on Democratic Participation provides a roadmap for voter registration reform.

A debate has opened up about the funding of electoral services with the Scottish Local Government and Communities Select Committee reviewing arrangements.

\section{Future threats}

Pilots to make voters show ID have been introduced in five local authorities at England's May 2018 local elections. Early academic studies showed that the pilots were 'unnecessary and ineffective.' Future pilots and the permanent compulsory requirement to introduce voter ID may follow, which could reduce turnout.

The Brexit process may still end up leaving many EU citizens resident in the UK with fewer electoral rights than they have had up to now.

Under the new Individual Registration systems electoral turnout and registration levels have so far held up. But they may drift downwards at subsequent elections without the transitional efforts to boost registration rates or high profile electoral events such as the Brexit referendum.

Political advertising, external boosting of particular campaigns, and other interventions via social media are currently very little regulated (see above). (See also Chapter 3.4.)

The Law Commission's proposals to consolidate the UK's 'complex, voluminous, and fragmented' sets of electoral law were published in February 2016 - and provides a blueprint for reforming electoral law. 


\section{Who is eligible to vote?}

The electoral franchise, which defines who has the right to vote, is an essential part of what it means to be a citizen within a polity. Excluding people from it immediately builds in political inequality, and can lend itself to partisan 'voter suppression' effort, as in many American states now.

The UK's electoral franchise is an antiquated patchwork of historical legacies that lacks any underlying principles. Citizens from qualifying Commonwealth countries and Ireland can move to the UK and have full electoral rights immediately. Yet a citizen from the European Union, who has lived and worked in the UK for most of their life, has rights for local and European elections (while they last) but not for parliamentary elections, nor for major electoral events like the EU referendum. Recent electoral events have affected them more than any other group of people.

We noted in the SWOT analysis that 16- and 17-year-olds can vote in all Scottish elections, and that this is planned for Wales, whereas these young people cannot vote in Westminster elections, or in any other part of the UK. Theresa May has since restated opposition to extending voting rights to 16 -year-olds. During the Brexit referendum lead-up, Lords amendments to grant 16 - and 17-year-olds the right to vote were rejected by the government, a decision that probably affected the result. Where Conservative governments have been proactive in expanding the franchise is for British overseas electors. The Overseas Electors Bill will give them votes for life, if passed (compared with the current system where expats retain the franchise only for the first 15 years that they live overseas).

Many recent electoral contests with profound consequences for public policy may have had entirely different electoral outcomes if UK franchise arrangements were different. Current provisions are largely unjustified, unbalanced and unequal. Meanwhile, the UK continues to breach the European Convention of Human Rights in denying prisoners (other than those on remand or serving sentences for contempt of court) any vote while serving their sentence.

\section{Fraud and malpractices}

The government ran pilots in five local authorities to require voters in England to present voter ID in the May 2018 local elections. But before those trials could be organised and the results analysed, the Conservatives rushed to make a manifesto commitment at the 2017 election to make this a permanent and compulsory reform. Critics argued that it could lead to many people being denied their right to vote because they do not have sufficient paperwork to hand on election day - or that voters would refuse to provide it on ideological grounds.

There is very little evidence that there is any significant voting fraud problem to justify the reform. Figure 2 shows data from a study of the 2018 English local elections which identifies the frequency of problems in polling stations. Suspicions of electoral fraud in polling stations was a tiny problem, and dwarfed by other problems. The overall number of fraud cases under the current 'high trust' system is exceptionally low. 
Figure 2: Problems experienced by poll workers at the English local elections 2018

Potential problem

People asking to vote but not on register

Disabled voters having problems completing ballot papers

Members of parties being where they shouldn't be

Disabled voters having problems with access to the polling station

People taking photos of ballot/ polling station

Members of parties intimidating public

People asking to vote whose identity I was unsure of

Suspected cases of electoral fraud
$\%$ of respondents reporting problem 52

Source: Clark and James, 2018. Note: \% exceeds 100 as workers can report more than one problem.

\section{The 'missing millions' of unregistered citizens}

Figure 2 also shows that the more significant problem was citizens turning up to vote only to find themselves not on the electoral register (although problems with accessibility for disabled voters are also common). Research shows that many citizens think they are registered because they access other government services and pay their council tax, when they often are not. Figure 3 below shows the number of people missing from the electoral register has gradually risen. If everyone was registered, the number of people on the electoral register should be roughly in line with the annual mid-year population estimates. But there has been a growing gap. And if there are duplicate register entries, which there are, many more people may be missing. One assessment suggests the overall number missed off could be up to eight million people.

Figure 3: The growing gap between the eligible number of citizens/inhabitants and total electors

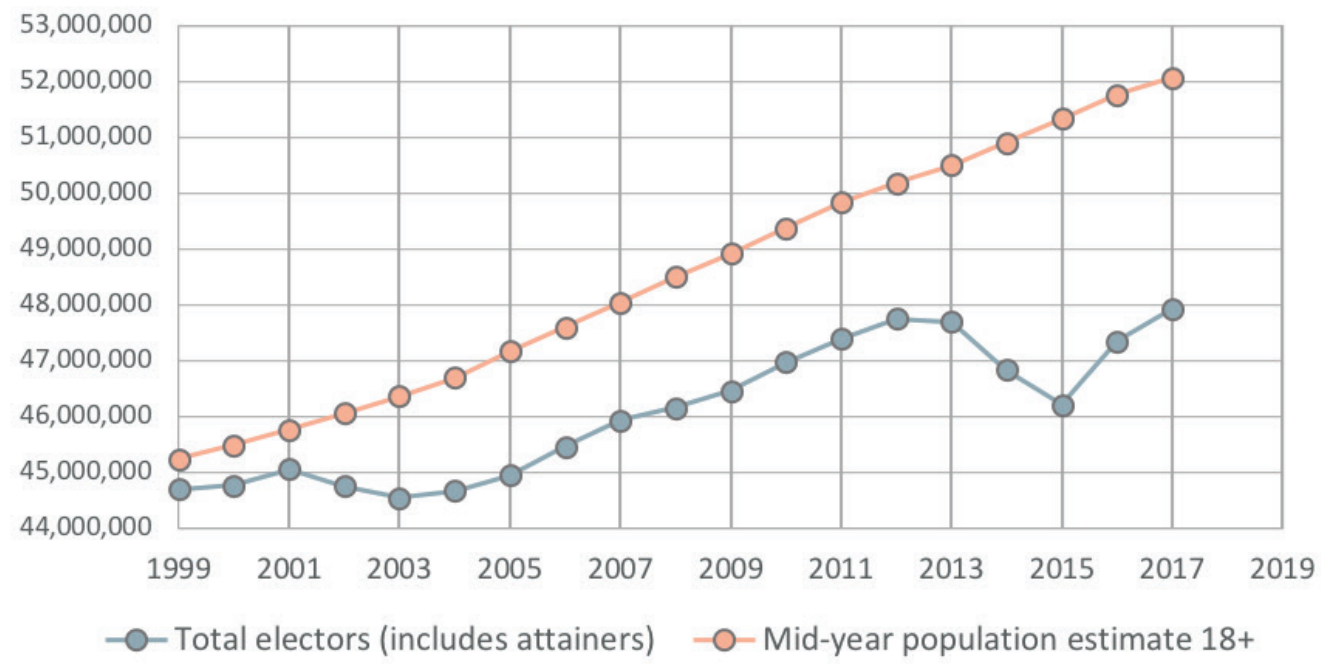

Source: Author compiled from ONS Population Estimates and Electoral Statistics from 1 December each year. The local electoral register is used because it has the higher franchise. 
Under-registration is not equally distributed across the whole population, fuelling further political inequality. Evidence shows the register is less complete in urban areas (especially within London, where three out of ten people under 30 move borough every year). This chiefly affects recent movers and private renters, Commonwealth and EU nationals, non-white ethnicities, lower socioeconomic groups, citizens with learning disabilities and young people.

The most worrying trend is with attainers - those citizens who will shortly reach the voting age during the currency of the forthcoming register. Historically this was just 16- and 17-year-olds, as only 18-year-olds can vote. But in Scotland and Wales attainers for devolved and local elections can now be 14 or 15. And Figure 4 shows that from 2009 there has been a decline in the number of attainer electors on the register (the grey line) compared with mid-year estimates of 16- and 17-year-olds in the UK (and including 14- and 15-year-olds in Scotland after 2015). Most of the next generation of voters already seem to be missing from the register.

Figure 4: The gap between eligible attainers (people nearing voting age, who should be on the electoral register) and registered attainers

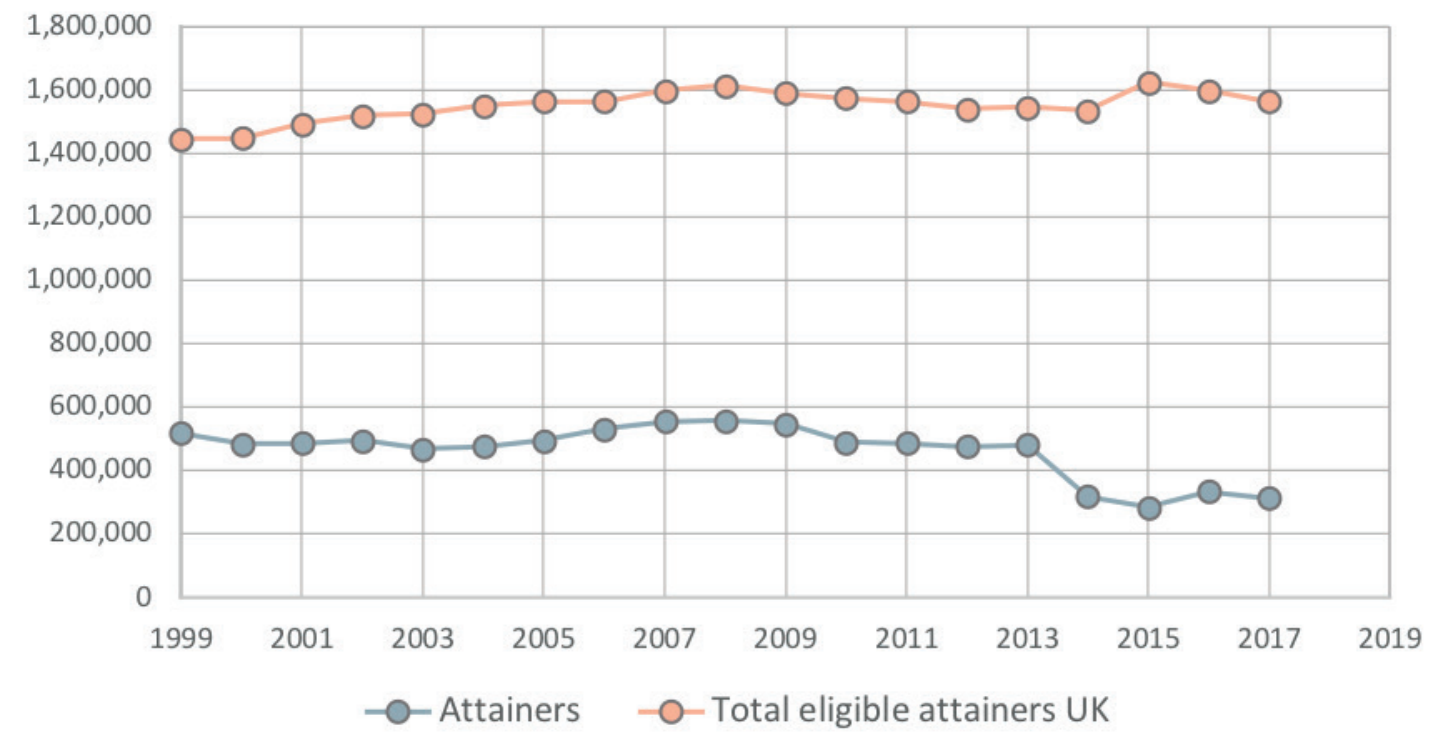

Source: Author compiled from ONS Population Estimates and Electoral Statistics. The local electoral register is used because it has the higher franchise.

Two effects are at work here. The move from household to individual electoral registration was predicted to hit young people the hardest since their parents often previously registered them, despite some counter-mobilisation efforts from civil society which helped to avert this in the short-term. Second, electoral registration efforts in Scotland may not have caught up with the new franchise. Simple solutions include the automatic registration of young people at other government 'touch points', for example, when they receive their national insurance card (needed for paid employment), or perhaps register for 
post-16 education. Legislation was recently passed to require universities to play a role in registering their students, one of the most under-registered groups. This may have a positive effect in the longer-run.

\section{Controlling election expenses at constituency level}

Despite efforts to monitor and regulate electoral campaign spending locally, 2015 saw allegations of significant breaching of electoral laws by 22 Conservative MPs and their agents not declaring 'national' spending in fact carried out in their local area. The Tories claimed that they had abided by the rules as set out, and never intended to breach requirements. The Electoral Commission found significant breaches and that the Tory party nationally showed an 'unreasonable' lack of co-operation with the Commission. Cases from 14 police forces were referred to the Crown Prosecution Service, which eventually only decided to press charges in one case.

Yet charges were not pressed in many cases, not because the affair was trivial but because of 'insufficient evidence to prove to the criminal standard that any candidate or agent was dishonest.' Critics question whether current legislation requires such a high (or impossible) threshold of evidence, that it is difficult to prevent loose interpretations from parties. In addition, there was a worrying effort by the governing Conservatives and the MPs involved to criticise and discredit the neutrality of the Electoral Commission in unwarranted ways, rather than to accept or respect the result of investigations. Such partisanship can only undermine confidence in the electoral process in the longer term. An additional new concern is that different requirements in Northern Ireland provide a backdoor for influencing election contests the UK.

\section{Reviewing Westminster constituency boundaries}

The Conservative-Liberal Democrat coalition government agreed that the size of the House of Commons should be reduced from 650 to 600 MPs, with the populations of constituencies to be equalised exactly. This would remove the previous tolerance for seats being only broadly similar in size because of community and other factors, which meant that the smallest constituencies were often in inner-city areas held by Labour, while the largest constituencies were in fast-growing outer urban areas. A boundary review was set in motion by the Parliamentary Voting System and Constituencies Act 2011. However, the Liberal Democrats subsequently withdrew co-operation on implementing the review, in response to Tory backbenchers wrecking House of Lords reform, and nothing further happened.

After the Tories gained a majority in 2015 fully equalised constituencies were revived and the Boundary Commission published proposals in 2017, redone after the 2017 election, with final details published in autumn 2018. Most estimates suggest that the Conservatives would make perhaps 20 seat gains from 600 equal sized constituencies, with Labour the chiefly loser. Yet some individual Tory MPs also risk seeing their established seats disappear, and may not be keen to see that happen. Some press reports in autumn 2017 suggested that the May government would drop the proposals (which would require re-legislating) altogether, since 
they are hard to get through a hung parliament. At the least, many observers expect that no new boundaries may come into effect by the next general election.

This might be a positive development for electoral integrity. One notable feature of the new boundaries was that they used the December 2015 electoral register to estimate populations - a snapshot of the electorate where millions were missing from the roll. Those geographic areas or groups who are under-represented on the register would therefore be under-represented in a new parliament.

\section{Conclusions}

Elections are an indispensable way for citizens to have popular control of government, and they are a fundamental foundation of political equality. At a time when democracy is thought to be under threat, achieving these objectives has never been more important. UK elections largely do this, but there are some underlying problems and new emerging threats which require reform in many areas.

Arguably, the paralysis caused by Brexit and the difficulties in legislating without a government majority, might excuse a government for not having the capacity to undertake the important changes. Nonetheless, some reforms, notably extending the franchise for overseas electors and introducing voter ID requirements, seem to be forthcoming. The problem, however, is that these do not speak in any way to the heart of the core electoral integrity challenges faced in the UK and to some extent worsen them.

Toby S. James is Head of Politics and Senior Lecturer at the University of East Anglia. He is Lead Fellow on Electoral Modernisation for the All Party Parliamentary Group on Democratic Participation and co-convenor of the Electoral Management Network. 